\title{
THE HALO EFFECT IN DESIGN TEACHING
}

\section{David MORGAN}

Brigham Young University

Keywords: Teacher bias, unconscious behaviour, error, positive/negative traits

\section{Unconscious Bias:}

Everyone has some degree of unconscious bias, which can influence how educators behave toward their students. It is important to acknowledge these biases exist and consciously work to minimize their effect on student learning.
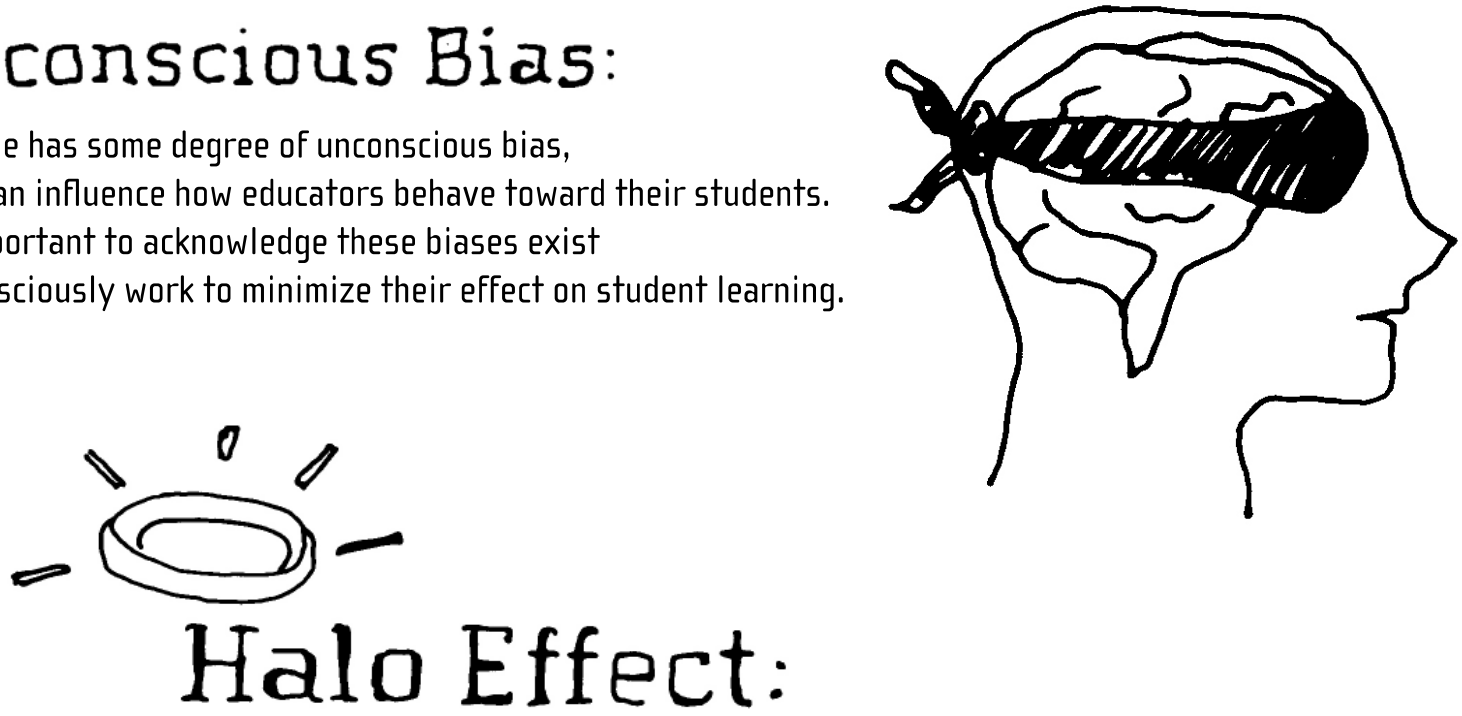

The halo effect is one form of unconscious cognitive bias. It is the tendency to generalize one outstanding personality trait to an overly favorable (or unfavorable) evaluation of the whole personality. It happens in the studio when professors are unable to discriminate between independent aspects of students' attributes and performance. We may like one student more than another, and therefore unknowinly treat them differently.

\section{Attractive $=$ Good}
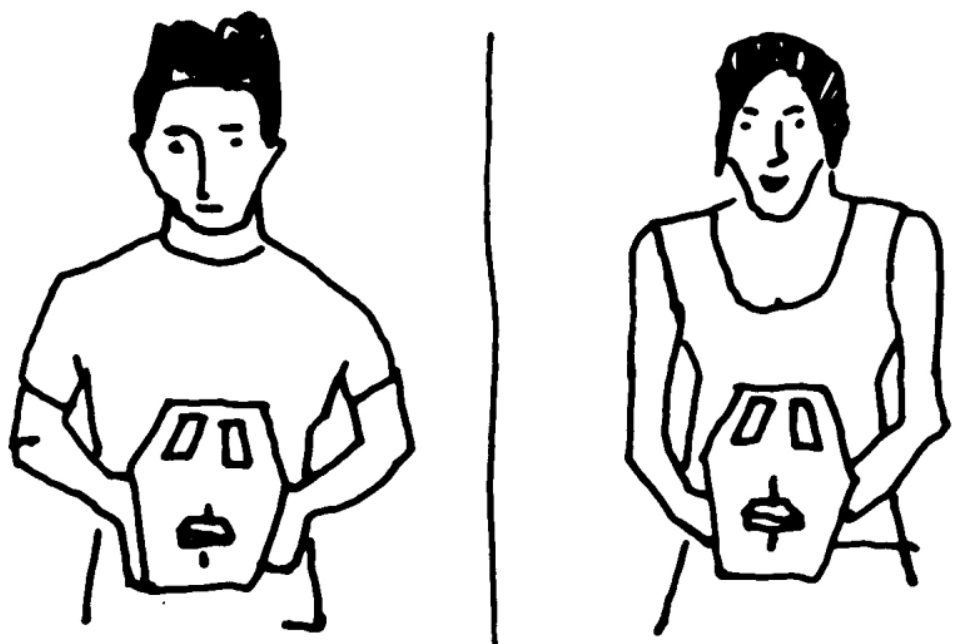


\section{Effects of the Effect}

On an individual level, educators can quickly form an impression of a student, based on a lifetime of cultural experiences--like breathing in a constant fog--and may have difficulty treating a student objectively thereafter. This halo effect can also function on a systemic level, based on ingrained but unconscious associations professors have with certain identity groups of students.[2]
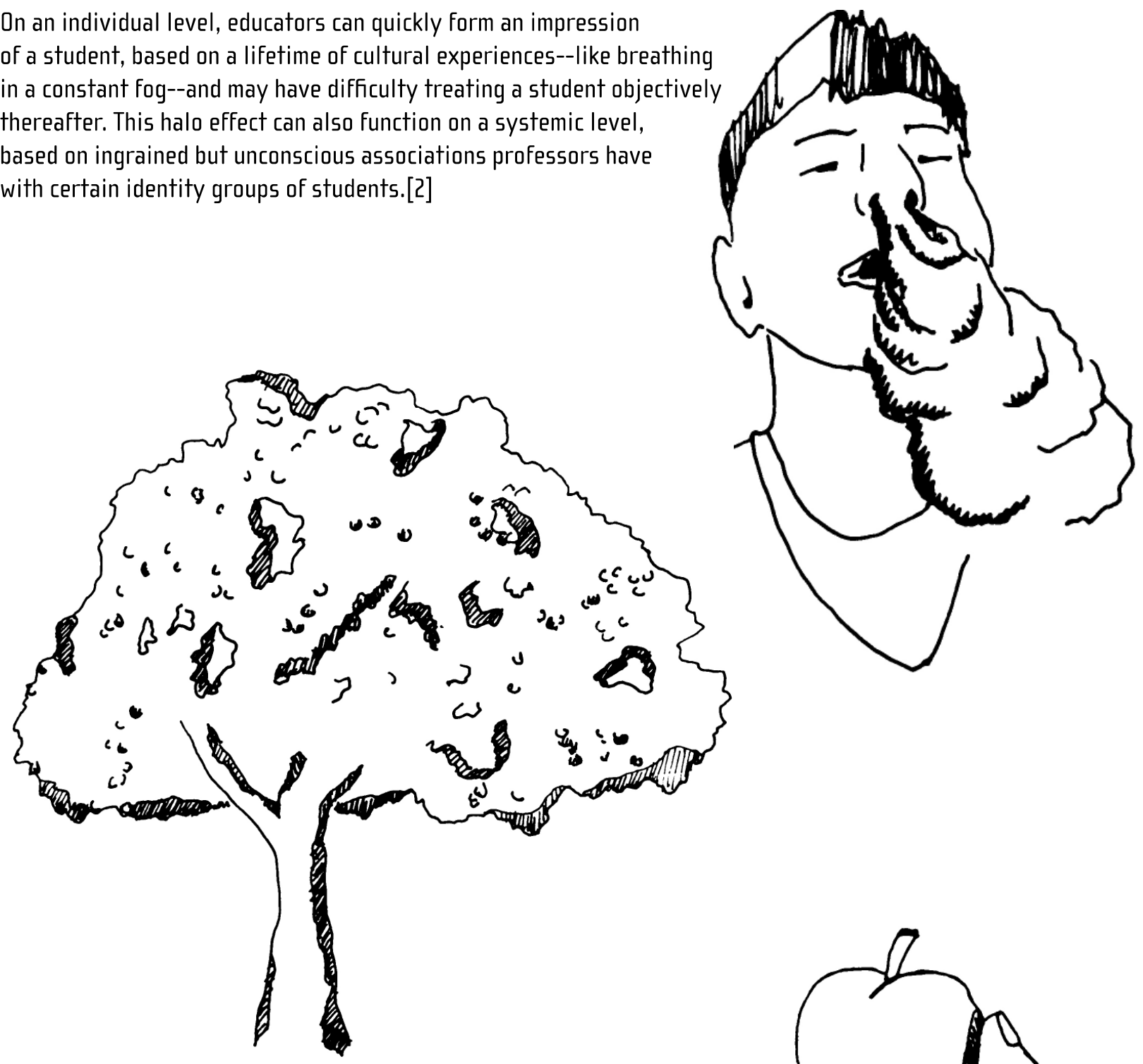

\section{Why It Happens}

The General Impression Model of why the halo effect occurs argues that a general impression of a student influences judgement and evaluation of that student in other unrelated dimensions. For example, if you are impressed with the overall appearence of a tree, you may be inclined to judge each fruit from that tree to be better than is objectively warranted. Another model, the Salient Dimensional model, proposes that assessment of an individual on one trait

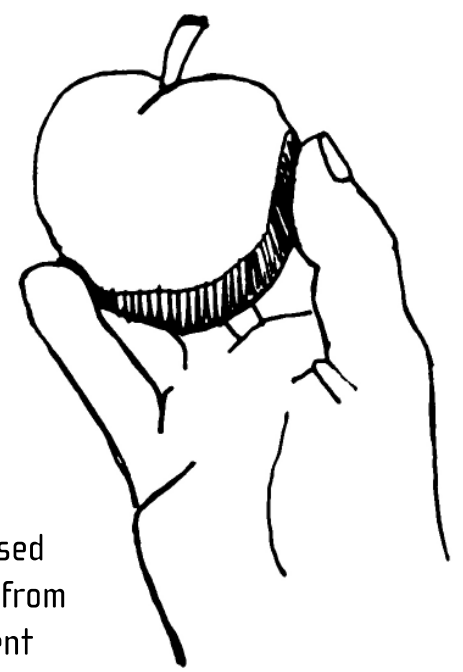
influences evaluations of that individuals' other traits.[3] 


\section{In Practice}

In some university courses the halo effed may be mitigated somewhat by blind assessment techniques. But in many studio courses, blind assessment is next to impossible because of ateacher's familiarity with students and their projects. For example, ateacher who has a strong making badkground, may makean unfairly positive evaluation of astudent who shares that interest, and also over-favor her well-crafted project, even when the design is somewhat deficient.

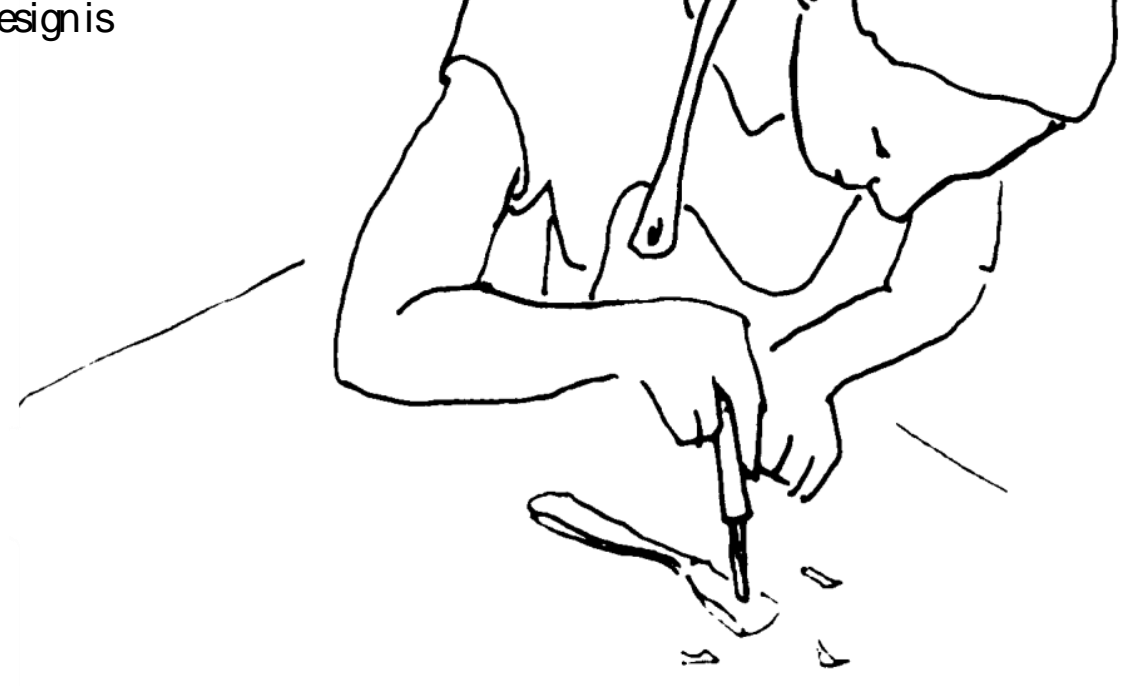

\section{Removing the Halo}

How can we minimize the hal o effect in our studio courses? We can slow down and be aware we may be biased.[4] Some introspection can beastart . It takestime and internal motivation to self-corred entrenched patterns of behavior .

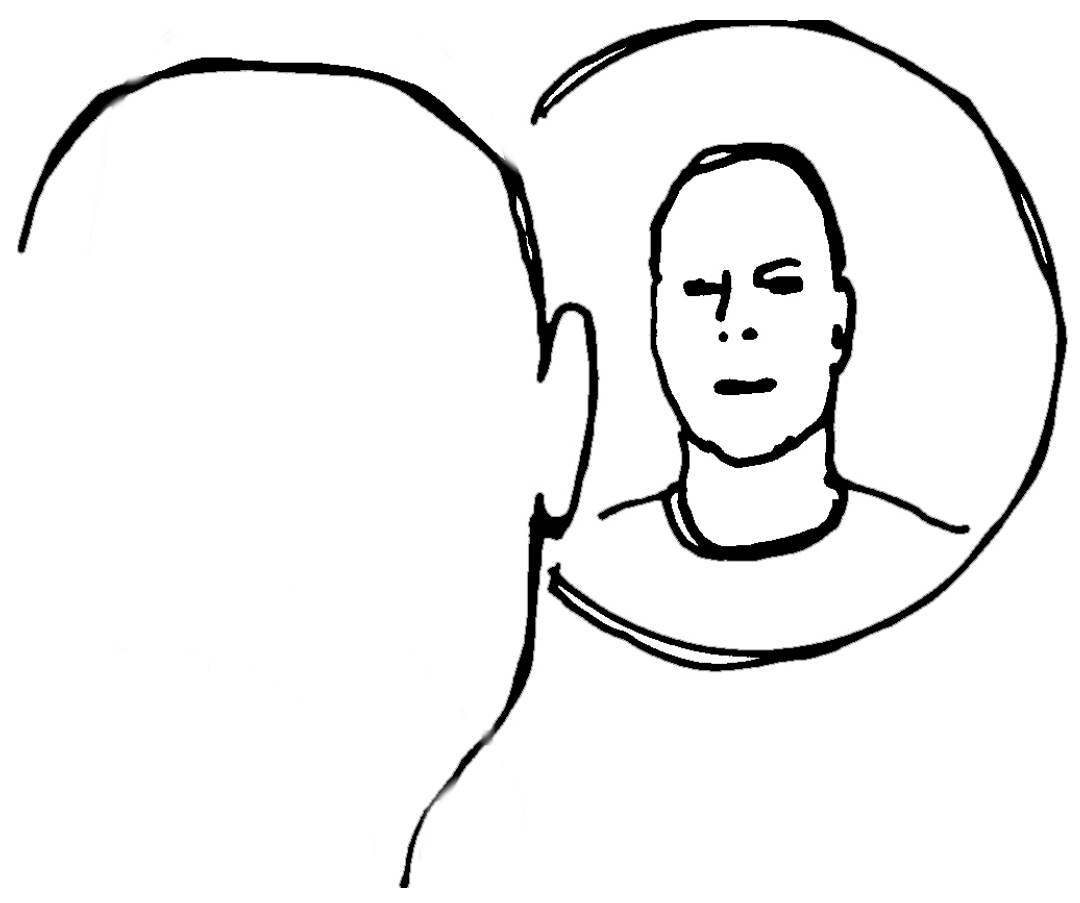


Conduct a self-audit with your own available data. Look at grade roll numbers

in terms of race, gender, and other dimensions. Analyze how various selections are made, and pay attention to critique time and frequency with students based on their identity.

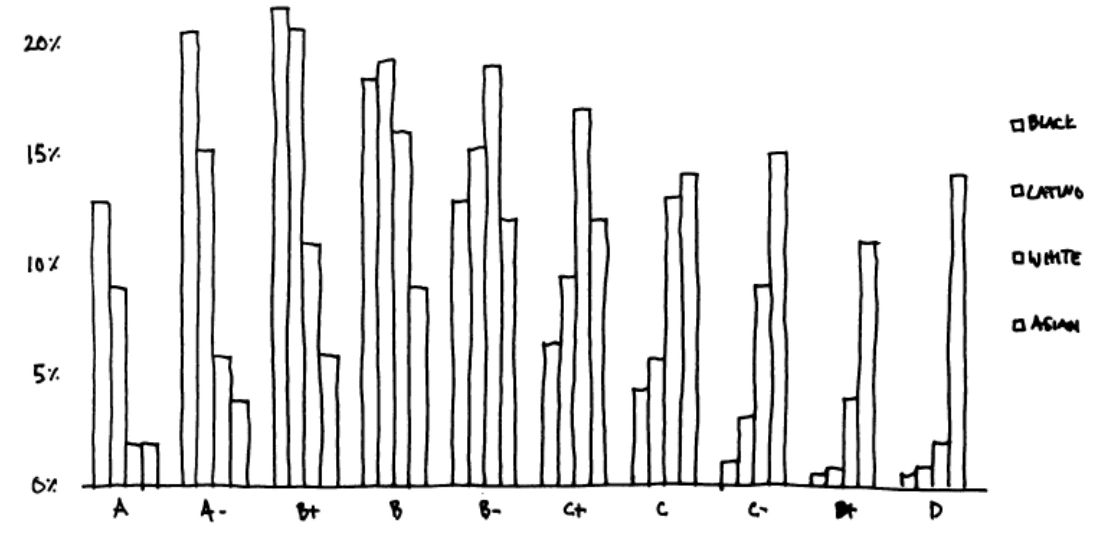

It might be a good idea to ask a colleague to observe your studio classes, paying attention to how you interact with your students, looking for how the halo effect may be present in your attitudes and behavior.

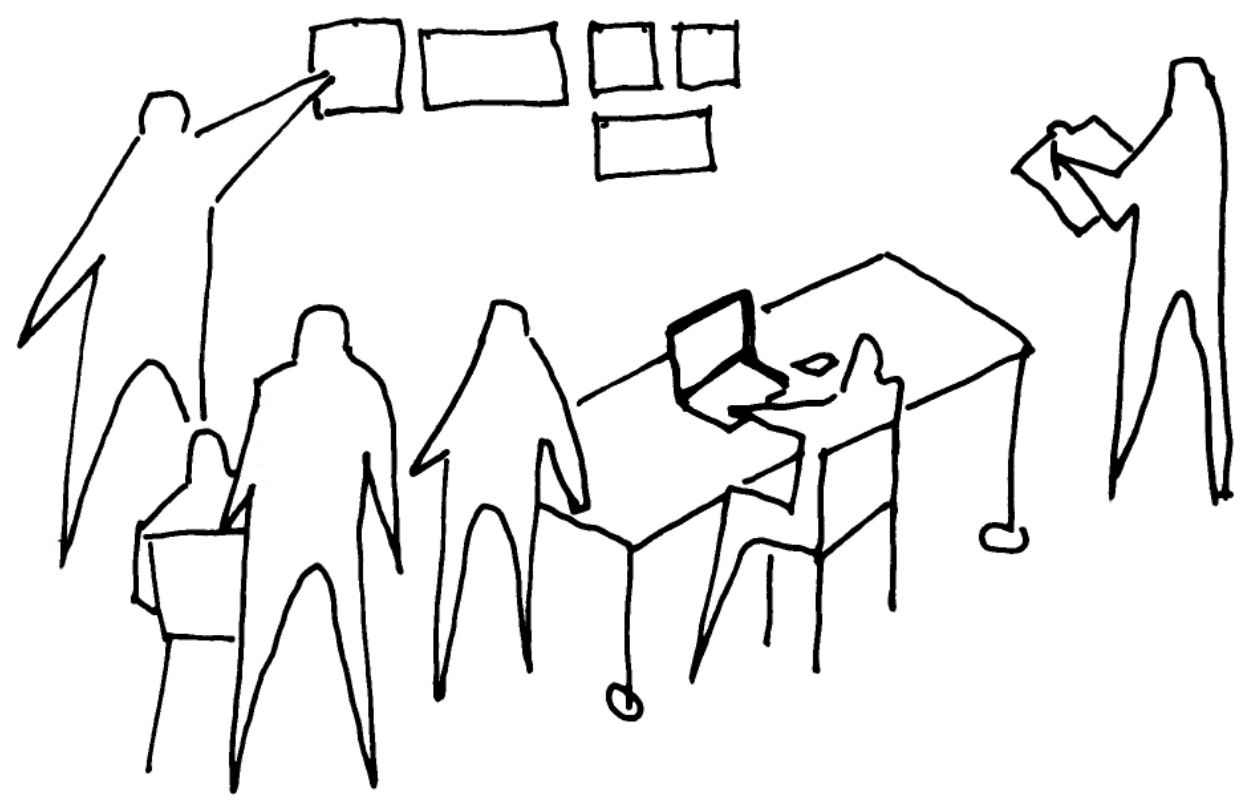

Even though the halo effect may be a pervasive problem, if we acknowledge it exists in our interactions, and take steps in the studio environment to reduce the negative results, we can create a more equitable learning environment.
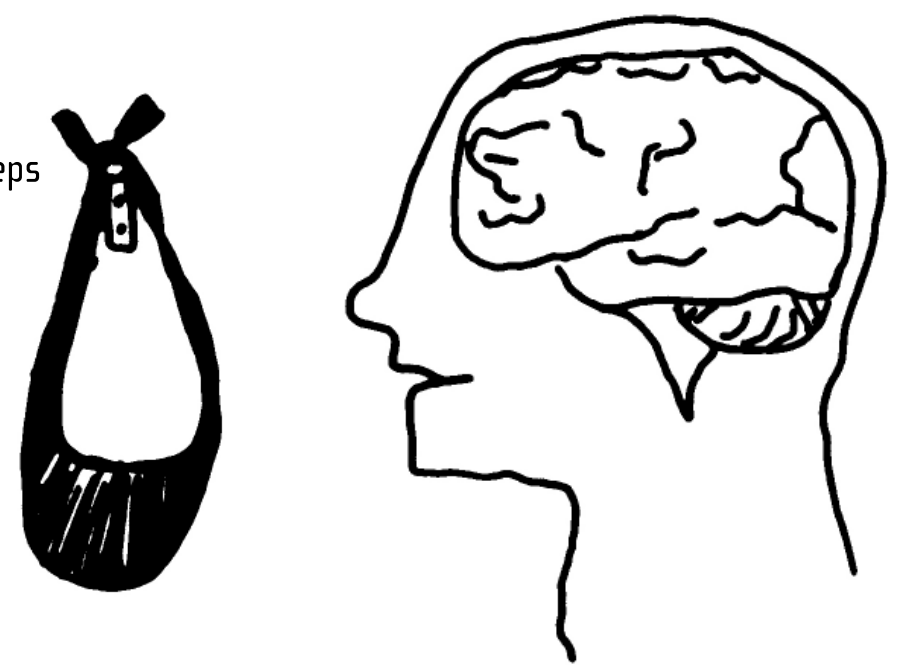


\section{REFERENCES}

[1] Thorndike EL. A Constant Error in Psychological Ratings. Journal of Applied Psychology, 1920, Vol 4, Issue 1 pp.25-29.

[2] Graf M. and Unkelbach C. Halo effect from agency behaviours and communion behaviours depend on social context. European Journal of Social Psychology, 2017, Vol 48, Issue 5 pp.701-717.

[3] Feeley T. Comment on Halo Effect in Rating and Evaluation Research. Human Communication Research, 2002, Vol 8, No. 4 pp.578-586.

[4] Gibson J. and Gore J. Is He a Her or a Weirdo? How Norm Violations Influence the Halo Effect. Gender Issues, 2016, Vol 33, pp.299-310. 